\title{
The role of host factors in measles virus persistence
}

\author{
Sibylle Schneider-Schaulies, Jens-Jörg Schnorr, Lee M. Dunster, Jürgen Schneider-Schaulies \\ and Volker ter Meulen
}

As critical steps in the life cycle of measles virus (MV), the efficiency of uptake into and replication in susceptible host cells are governed by cellular determinants. Measles virus infections of cells of the human CNS are characterized by particular constraints imposed on viral transcription and translation attenuating viral gene functions and thus contributing to the pathogenesis of $M V$ persistence in these cells.

Key words: CNS infection / MV receptor / MV transcription / unwindase

COMPLICATIONS OF acute measles are frequent, most of them are linked to virus-mediated cytolysis of the primary target cells, the peripheral blood mononuclear cells (PBMCs), and indirect mechanisms based on the temporary virus-induced immunosuppression as well as virus-induced autoimmune reactions. ${ }^{1-3}$ Although not convincingly confirmed experimentally, persistent infection of lymphocytes or monocytes has been suggested for the pathogenesis of MV associated disease processes including CNS complications. ${ }^{4,5}$ Subacute sclerosing panencephalitis (SSPE) and, in immunocompromised hosts, measles inclusion body encephalitis (MIBE) develop on rare occasions months or years after primary infection based on persistence of virus in neuronal and glial cells. ${ }^{6}$ Both lethal conditions are characterized by the absence of free infectious virus in brain tissue due to a defective intracellular replication cycle which allows the virus to survive in a cell associated form and inaccessible to the host immune surveillance. ${ }^{1}$ This is generally achieved by maintaining the integrity of the viral protein functions associated with ongoing transcription and intracellular replication and attenuating or abolishing the expression of the viral envelope proteins. The restrictions of the latter have been linked to a generally low abundance of the corresponding

From the Institute for Virology, University of Würzburg, Versbacher Strasse 7, D-97078 Würzburg, Germany

(C) 1994 Academic Press Ltd

$1044-5773 / 94 / 040273+08 \$ 8.0010$
mRNAs in brain tissue and to the fact that many of the envelope gene sequences known today harbor mutations interfering with functional expression of the gene products ${ }^{6,7}$ (Table 1).

Although mutations within the envelope gene sequences are undoubtedly important for controlling viral gene functions in persistent MV CNS infections, the presence of MV wild-type-like sequences in SSPE brain material provided a strong argument for a nondefective virus initially infecting the CNS. ${ }^{8}$ Thus, the primary virus-host cell interaction probably is governed by host cell factors attenuating viral gene functions thereby abolishing a lytic, productive replication and enabling the establishment of a persistent infection.

In this review we will focus on basically two distinct events in the viral replication cycle which are determined to a major extent on host cell dependent factors, namely the interaction of $\mathrm{MV}$ with its cellular receptors and intracellular regulatory events interfering with the synthesis and functionality of virus-specific transcripts.

\section{MV receptor interactions}

The first events determining the cell tropism of MV in vivo are receptor mediated entry of the virus, subdivided into specific attachment, close binding and subsequent fusion between viral and host cell membrane and ultimately, the release of the viral genetic material into the cytoplasm (shown schematically in Figure 1). It was not until recently that two different cell surface molecules have been identified on tissue culture cells that are functionally associated with infectivity of the cell with MV. Antibodies raised against CD46 (membrane cofactor protein, expressed on the surface of most human cells) ${ }^{9}$ were able to interfere with MV infection. ${ }^{10,11}$ Upon stable transfection of CD46, certain mouse cell lines were capable of supporting productive MV replication, whereas others were not, ${ }^{10}$ indicating that CD46 would be necessary but not sufficient to confer susceptibility to MV infection. ${ }^{10,11}$ More recently, as a second 
Table 1. Alterations of MV gene functions in persistent brain infections

\begin{tabular}{|c|c|c|}
\hline Replication step & Alterations in persistent infections & Consequences \\
\hline Transcription & $\begin{array}{l}\text { Highly polar expression gradients } \\
\text { for monocistronic mRNAs } \\
\text { Increased frequency of bicistronic } \\
\text { mRNAs }\end{array}$ & $\begin{array}{l}\text { Low abundance of the envelope and polymerase } \\
\text { proteins } \\
\text { Inefficient translation of the second reading frame }\end{array}$ \\
\hline $\begin{array}{l}\text { Function of viral } \\
\text { mRNAs and } \\
\text { proteins }\end{array}$ & $\begin{array}{l}\mathbf{N}, \mathbf{P}, \mathbf{L} \text { proteins: } \\
\text { few expressed point mutations over } \\
\text { the entire genes } \\
\mathbf{M} \text { proteins: } \\
\text { point mutations and hypermutations } \\
\text { over the entire coding sequence } \\
\mathbf{F} \text { proteins: } \\
\text { C-terminal point mutations } \\
\text { H proteins: } \\
\text { point and hypermutations }\end{array}$ & $\begin{array}{l}\text { Alterations of the polymerase activity? } \\
\text { Altered protein/protein interactions? } \\
\text { Antigenic changes } \\
\text { M proteins absent, truncated or instable } \\
\text { Defective budding? } \\
\text { Alterations of NC binding? } \\
\text { Truncation, distortion of the C-terminal domain } \\
\text { Loss of glycosylation sites } \\
\text { Impaired dimerization and membrane transport } \\
\text { Reduced hemadsorption activity } \\
\text { Antigenic changes }\end{array}$ \\
\hline
\end{tabular}

Summarized are alterations of MV gene functions defined directly in brain material of patients with persistent CNS infections or by analyzing MVs isolated from brain tissue by cocultivation and propagated as 'SSPE isolates' in persistently infected tissue culture cells. Transcriptional attenuation has generally been observed affecting both overall MV transcription levels (as determined as copy numbers $/ 10 \mathrm{pg}$ of total RNA) as well as the formation of highly polar expression gradients for the downstream mRNAs. ${ }^{19,20}$ Functional impairments of these mRNAs, mainly due to point and hypermutations, alter, trunca:e, destabilize or completely abolish the corresponding translation products. ${ }^{6,7}$ While functional consequences for the alterations within the $N, P$ and $L$ proteins are anticipated, they have been experimentally addressed for the envelope proteins recently. ${ }^{73-75}$

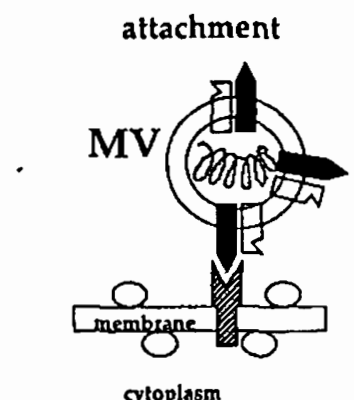

host cell
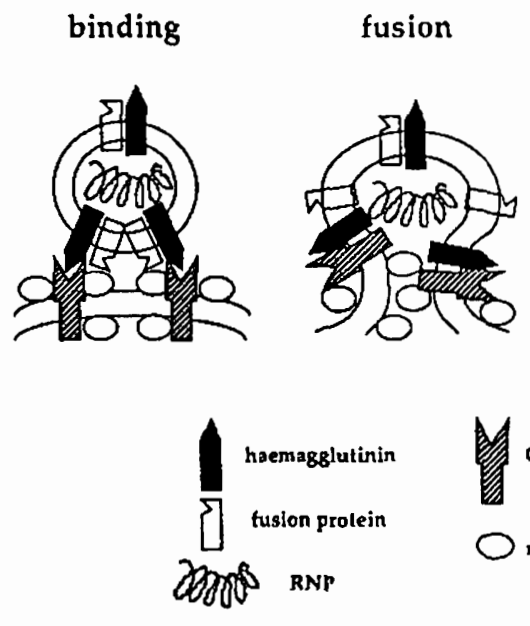

IRNP release

and

replication

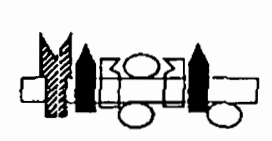

200

Figure 1. Steps in measles virus-cell interactions. Binding of enveloped viruses to cells and subsequent fusion is a multistep mechanism not well understood. The model predicts that complexes of CD46 and moesin and MV-H and F are required for efficient uptake of MV by cells. While the interaction of MV-H protein with CD46 is strongly suggested, ${ }^{10}$ the interaction of the $\mathrm{F}$ protein with one of these components has not been established. Note also, that CD46 is a classical transmembrane glycoprotein, ${ }^{9}$ whereas moesin is associated with both surfaces of the cellular membrane, however, has no typical transmembrane domain. ${ }^{12}$ Following release of the viral RNP, factors within the cytoplasmic compartment determine the susceptibility of the host cell. 
molecule, moesin (membrane, organizing external spike protein, widely expressed on eucaryotic cells $)^{12}$ could be linked to MV susceptibility in a variety of tissue culture cells. ${ }^{13}$ Monoclonal antibodies against both constituents efficiently blocked infection with MV, but not with viruses as closely related as CDV in tissue culture ${ }^{10,13}$ and recently, data accumulated suggesting that both molecules are part of the functional receptor complex for MV (J. Schneider-Schaulies, unpublished). Both molecules reveal a wide tissue distribution in vivo, 9,12 but only certain isoforms of CD46 have been detected on the surface of brain cells. ${ }^{14}$

A role of the receptor in determining the outcome of a viral infection has also been suggested. For HPIV 3, removal of the receptor during infection has been linked to a persistent state by preventing cell-cell fusion. ${ }^{15}$ The establishment of persistence upon limitation of the receptor has also been observed for HIV. ${ }^{16}$ In a cell line persistently infected with $M V$, cell-cell fusion did not occur unless fresh cells were added to the culture ${ }^{17}$ and recently it was shown that infection with $M V$ or a recombinant vaccinia virus expressing the $\mathrm{MV} \mathrm{H}$ protein led to a down-regulation of CD 46 molecules at the cell surface ${ }^{10}$ and, in fact, significantly reduced amounts of $\mathrm{CD} 46$ and moesin were detected on the surface of persistently $M V$-infected human monocytes (ref 13; L.M. Dunster, unpublished). Functional consequences of removal of CD46 proteins from the cell surface may include an increased vulnerability of the infected cells to complement lysis (J.-J. Schnorr, in preparation). On the other hand, their reduced fusability could favor the establishment of viral persistence. Since, however, a strict correlation was found between the degree of down-regulation of CD46 and the amount of the $\mathrm{H}$ protein, the latter hypothesis will probably not refer to brain cells where the expression of the envelope proteins is generally restricted (see below).

Further characterization of the MV/cell receptor-interactions and the establishment of stably transfected cell lines or transgenic mouse lines will, however, contribute not only to the understanding of the pathogenesis of $\mathrm{MV}$, but also to evaluate the role of intracellular factors controlling the permissiveness of the host cell. In fact, although extensive formation of syncytia was observed after infection with a vaccinia virus recombinant encoding both $M V F$ and $H$, mouse $L$ cells constitutively expressing CD46 were not permissive for MV indicating a block of $\mathrm{MV}$ replication later than at the level of entry. ${ }^{10}$

\section{Control of intracellular MV gene expression in brain cells}

Alterations of MV gene expression have mainly been characterized directly using autopsy brain material of SSPE and MIBE patients and cell lines persistently infected with MV isolates obtained by cocultivation from brain tissue. ${ }^{18}$ To investigate the particular virus-host interactions governing the primary infection as experimental systems, an animal model for experimentally induced MV-CNS infections in rats and tissue culture systems with primary and permanent cell lines of neural origin have been used.

\section{Regulation of $M V$ transcription}

Transcription of viral subgenomic mRNAs is initiated by the transcriptase complex at a promoter site within the $3^{\prime}$ noncoding region and subsequently the individual $m R$ NAs are synthesized. The polymerase tends to detach from the template at the intergenic regions with increasing frequency to the $5^{\prime}$ end of the genome leading to a polar accumulation of viral mRNA transcripts in vivo and in vitro. ${ }^{19-21}$ In SSPE brain material, this gradient appears to be 40 -fold steeper 19,20 leading to a considerable reduction in $\mathrm{M}, \mathrm{F}$ and $\mathrm{H}$ protein expression which has been directly documented ${ }^{22}$ (Table 1 ).

In analyzing potential host factors it became evident that in brain cells the overall MV specific transcription is substantially reduced as indicated by the steady-state levels of the $\mathrm{N}$-specific transcripts per infected cell. In MV-infected human neural tissue culture cells and primary rat astroglial cells, these transcripts were up to tenfold less abundant compared to nonneural cells under identical conditions. ${ }^{23,24} \mathrm{~A}$ further reduction of the overall $\mathrm{MV}$ transcription has been linked to the differentiation state of the infected cells in brain material of both experimentally infected animals and in tissue culture of human neuroblastoma cells treated with differentiating compounds. ${ }^{25,26}$ Concomitant with the overall reduction observed, the progressive decrease of the mRNA frequency along the gene order, typical for SSPE, could also be detected in tissue culture systems using neural cells 
and in brain tissue of experimentally infected animals. ${ }^{24,27}$

\section{Antibody-induced antigenic modulation}

Transcriptional attenuation of $\mathrm{MV}$ in brain cells may also be supported by exogenous factors such as virus-neutralizing antibodies. A significant down-regulation of $\mathrm{MV}$ transcription was observed in experimentally infected newborn animals compared to naive controls after passive transfer of neutralizing anti-H-antibodies. ${ }^{25}$ In the presence of neutralizing antibodies, a pronounced reduction of the expression of all MV structural proteins within few days was observed in persistently MV-infected rodent neural cells, but not in Vero cells or human lung fibroblasts. ${ }^{28-30}$ RNA analyses revealed that $24 \mathrm{~h}$ after the application of antibodies, total MV transcriptional efficiency was reduced up to tenfold whereas the relative frequencies of the 5' mRNAs were substantially unaffected..$^{30}$ Although 'antibody induced antigenic modulation (AIAM)' has recently been shown to account also for restrictions of other viruses, ${ }^{31}$ the signal transduction pathways involved have not been investigated. An immediate, temporary increase in phosphoinositol breakdown and stimulation of the protein kinase $\mathrm{C}$ has been described following addition of an anti-H antibody to persistently MV-infected rat glioma cells, ${ }^{32}$ whereas other investigators observed a down-regulation of protein kinase $\mathrm{C}$ activity upon treatment of a persistently infected mouse neuroblastoma cell line with MV hyperimmuneserum. ${ }^{33}$ Protein kinase $\mathrm{C}$ mediated alterations of $\mathrm{MV}$ gene expression in neural cells have not been investigated so far. In PBMCs, stimulation of protein kinase C by TPA (phorbol myristate acetate) or the $\mathrm{Ca}$ ionophore 23187 led to the activation of MV replication. ${ }^{34}$

\section{Role of the human IFN-inducible $M x A$-protein in regulating $M V$ gene expression}

Cytokines released from $\mathrm{MV}$-infected brain cells may interfere additionally with viral as well as cellular gene expression. ${ }^{35}$ Amongst those, the antiviral potential of type I IFN and the well characterized IFN-inducible proteins has been a matter of more detailed investigations. ${ }^{36-39}$ One of the latter, the type I IFN-inducible MxA protein, has recently been linked to transcriptional attenuation of MV brain cells, but not in nonneural cells. ${ }^{39}$ MxA-dependent downregulation of MV transcription affected both overall efficiency and the relative frequencies of the $5^{\prime}$ mRNAs, whereas the same protein expressed in the human monocytic cell line U-937 specifically inhibited the synthesis of the MV glycoproteins in the absence of any detectable transcriptional control. ${ }^{40}$ it is quite remarkable that the antiviral activity of the MxA protein seems to be quite complex, as previous studies revealed a host cell independent MxA-mediated inhibition of VSV RNA synthesis. ${ }^{40,41}$ Since, however, high levels of $\mathrm{MxA}$ are detected in monocytes and brain cells during primary or persistent MV infection respectively, this protein apparently bears a high potential to act as a host cell specific factor attenuating $M V$ gene expression.

\section{Potential mechanisms and targets of $M V$ transcriptional regulation}

As appropriate experimental systems are not at hand, mechanisms contributing to $M V$ transcriptional regulation are still largely unknown. For MV and related viral systems, evidence for a role of cytoskeletal components like tubulin for efficient replication has been provided in vitro. ${ }^{21,42,43}$ Due to their ubiquitous expression, the linkage of these proteins to host cell dependent transcriptional regulation is not obvious. More recently, uncharacterized host proteins directly binding to the leader RNA of MV have been proposed to play a role in determining permissivity for $\mathrm{MV}$ on a transcriptional level. ${ }^{44}$ Alternatively, host cell specific modifications of viral proteins essential for transcription and replication could be envisaged. As shown for vesicular stomatitis virus (VSV), at least one of the functionally required phosphorylation events of the viral $P$ protein is due to the action of a cellular kinase and an inhibition of that kinase activity directly correlates with transcriptional inhibition in vitro. ${ }^{45,46}$ It is well established that at least three MV proteins (N, $\mathrm{P}$ and the nonstructural $\mathrm{V}$ protein) are phosphorylated, exact phosphorylation sites, however, and their functional importance have not been defined. ${ }^{47-49}$

Although the polymerase protein $\mathrm{L}$, is probably just required in catalytic amounts, its low abundancy due to the under-representation of the corresponding transcript, may be limiting for transcriptional efficiency in brain cells. A certain stoichiometry of $\mathrm{N}, \mathrm{P}$ and $\mathrm{L}$ proteins for the formation of functional complexes has been shown to be required for the related Sendai virus system. ${ }^{50}$ In addition, an inhibitory capacity of the Sendai virus $V$ protein on 
viral RNA replication was found in vitro with the $L$ protein being limited. In the presence of strongly polar expression gradients for the corresponding transcripts, $V$ protein may exert a negative effect on replication in infections where the concentration of $\mathrm{L}$ is relatively low, such as in brain cells. ${ }^{51}$ Thus, although editing required for the synthesis of the $\mathrm{V}$ protein is most presumably an activity intrinsic to the viral polymerase and independent of host cell factors, ${ }^{52}$ the gene function(s) of the editing product may be regulated by the host background.

\section{Biological activity of virus-specific transcripts}

\section{Mutational alterations}

In addition to altering the relative frequencies of virus-specific transcripts, their translational activity provides an important site of control for viral gene functions. From the analyses of envelope gene specific mRNAs from persistent brain infections it became apparent that most of the restrictions on translational level are based on sequence mutations leading to premature termination or complete abolishment of the corresponding reading frames. ${ }^{7,18}$ An exception is provided by the M-specific mRNAs isolated from the brain of experimentally infected Lewis rats with SAME, that were not translated in vivo and in vitro, independent of detectable sequence alterations. ${ }^{27}$

In addition to point mutations as introduced by the viral polymerase during the long lasting virus-host interactions, a second type of mutations involving simultaneous clustered transitions of several uridine (U) to cytidine (C), or, less frequent, adenosine (A) to guanosine (G) residues, specified in the plus strand sense, has been encountered predominantly in the M genes of SSPE and MIBE cases and persistently infected tissue culture cells. , $^{8,53-55}$ These hypermutation events have been ascribed to the activity of a double-strand (ds) RNA dependent unwinding/modifying enzyme, now referred to as DRADA (double-strand RNA specific adenosine desaminase) intrinsic to the host cell. ${ }^{54,56,57}$ The model predicts that A residues would be desaminated to yield inosine (I) in MV-specific dsRNAs during transcription. Subsequently, within the first round of replication, the modified I residues would base pair with $\mathrm{C}$ replacing the primary $\mathrm{A} / \mathrm{U}$ pairing.

The potential importance of this cellular activity in silencing MV gene functions has been recently supported by the characterization of several evolved hypermutated sequences within different brain areas of a case of SSPE. ${ }^{8}$ As obvious from that study, a wild-type like $M$ sequence was actively modified in the course of the infection by several discrete, consecutive hypermutation events. Moreover, evidence for hypermutation of viral genes has been provided for viral systems other than MV. ${ }^{58-60}$ In vitro, the activity could be detected in a variety of mammalian tissue culture cells without an apparent template specificity. ${ }^{61-63}$ The intracellular localization of the activity has been shown to be dependent on the cell cycle ${ }^{61,62}$ usually being extremely low under growth arresting conditions. ${ }^{61}$ An MV M specific subgenic fragment has been successfully modified in vitro in nuclear extracts of a human neuroblastoma cell line (IMR-32) but not of Vero cells. ${ }^{64}$ More recently, the presence and activity of the enzyme in cytoplasmic extracts of in vitro differentiated brain cells has been confirmed. ${ }^{65}$ Thus, although the further propagation of the mutated viral sequence is completely dependent on their impact on viral gene functions, the basic attenuation is dependent on host cell rather than viral determinants.

\section{Translational control independent of mutations}

Apart from mutational events discussed above, translational efficiency may depend on $5^{\prime}$ and $3^{\prime}$ noncoding sequences of a mRNA interacting with common or host cell specific cellular RNA binding proteins. ${ }^{66} \mathrm{~A}$ temperature shift of persistently infected rat glioma cells led to a selective and reversible translation inhibition of $\mathrm{MV} M$ and $\mathrm{F}$-specific mRNAs arguing strongly for the involvement of cellular determinants in controlling viral gene functions. ${ }^{67}$ Similar observations of translational inhibition affecting partial as well as complete, MV protein synthesis have been described as a consequence of in vitro differentiation of tissue culture cells of neural origin. ${ }^{24,26,68}$ In one of these studies, in vitro differentiation of human glial cell lines prior to MV infection led to an almost complete block of viral protein synthesis in vivo, whereas the synthesis of the corresponding mRNAs and their ability to direct the synthesis of translation product in vitro were apparently unaffected. ${ }^{24}$ In addition, the overall protein synthesis of the infected cells was not inhibited. The obvious specific inhibition of viral rather than cellular gene expression is reminiscent of that described for the antiviral activity of certain IFN-induced proteins. ${ }^{69}$ Although as a consequence 
of MV infection the induction of IFN is indicated by the expression of human $\mathrm{MxA}$ in these cell lines, ${ }^{35}$ in vitro differentiation did not lead to a detectable stimulation of IFN synthesis arguing against a pronounced inhibitory effect brought about by $P 1$ kinase. ${ }^{24}$ The sensitivity of $M V$ specific protein expression to exogenous treatment with IFN- $\alpha$ independent of viral mRNA down-regulation was shown in PBMCs. ${ }^{70}$

\section{Conclusions and future perspectives}

As outlined above, host cell dependent attenuation of MV gene expression and functions on different levels may be of crucial relevance in favoring the establishment of persistent infections. An additional role for viral constituents in this process cannot, however, be excluded. Recently, the clonal expansion of a MV identified by a hypermutated $M$ sequence in the brain of one SSPE patient has been suggested to be based on a selective advantage of this particular isolate. ${ }^{8}$ To evaluate and characterize the role of viral and cellular determinants in the pathogenesis of human CNS infections, a precise definition of functional domains within the viral structural proteins required for intracellular amplification of viral genetic material and the maturation and release of viral particles will be indispensable. So far, the C-terminal domain of the MV P protein has been identified as necessary for complex formation of $\mathrm{MV} \mathrm{N}$ and $\mathrm{P}$ proteins in vivo, ${ }^{71}$ and the binding of MV M protein to MV RNP complexes has been investigated in vitro. ${ }^{72,73} \mathrm{As}$ for influenza virus and VSV, a role for that protein has been proposed in regulating MV transcription. ${ }^{74}$ Ultimately, the MV-glycoprotein-dependent membrane fusion has been investigated in tissue culture. ${ }^{75}$ Understanding of MV protein functions and the relevant domains will allow the evaluation of alterations within these proteins sequences encountered in persistent infections and their potential contribution to this particular virus-host interaction.

\section{Acknowledgements}

The authors thank the Deutsche Forschungsgemeinschaft, the Humboldt-Stiftung and the Bundesministerium für Forschung und Technologie for generously supporting their laboratory work.

\section{References}

1. ter Meulen V, Carter MJ (1982) Morbillivirus persistent infections in animals and man, in Virus Persistence (Mahy BWJ, Minson AC, Darby GK, eds), pp 97-132. Cambridge University Press, Cambridge

2. Moench TR, Griffin DE, Obriecht CR, Vaisberg A, Johnson RT (1988) Distribution of measles virus antigen and RNA in acute measles with and without neurologic involvement. J Infect Dis 158:433-442

3. Schneider-Schaulies S, Kreth HW, Hofmann G, Billeter MA, ter Meulen V (1991) Expression of measles virus RNA in peripheral blood mononuclear cells of patients with measles, SSPE, and autoimmune diseases. Virology 182:703-711

4. Cosby SL, Macquaid S, ' Taylor MJ, Bailey M, Rima BK, Martin SJ, Allen IV (1983) Examination of eight cases of multiple sclerosis and 56 neurological and nonneurological controls for genomic sequences of measles virus. J Gen Virol $70: 2027-2036$

5. Cosby SL (1993) Measles virus: a possible tole in various diseases of unknown origin. Microbiol Eur 5:22-26

6. Schncider-Schaulies S, ter Meulen V (1992) Molecular aspects of measles virus induced central nervous system diseases, in Molecular Neurovirology (Roos RP, ed), pp 419-449. Humana Press, Clifton, NJ

7. Billeter MA, Cattaneo R, S̄pielhofer P, Kaelin K, Huber M, Schmid A, Baczko K, ter Meulen V (1994) Generation and properties of measles virus mutations typically associated with subacute sclerosing panencephalitis. Ann NY Acad Sci, in press

8. Baczko $\mathrm{K}$, Lampe J, Liebert UG, Brinckmann U, ter Meulen V, Pardowitz I, Budka H, Cosby SL, Isserte S, Rima BK (1993) Clonal expansion of hypermutated measles virus in a SSPE brain. Virology 197:188-195

9. Liszweski MK, Post TW, Atkinson JP (1991) Membrane cofactor protein (MCP or CD46): newest member of the regulators of complement activation gene cluster. Annu Rcv Immunol 9:431-455

10. Naniche D, Varior-Krishnan G, Cervoni F, Wild TF, Rossi B, Rabourdin-Combe C, Gerlier D (1993) Human membrane cofactor protein (CD46) acts as cellular receptor for measles virus. J Virol 67:6025-6032

11. Doerig RE, Marcil A, Chopra A, Richardson CD (1993) The human CD46 molecule is a receptor for measles virus (Edmonston strain). Cell 75:295-305

12. Furthmayer HW, Lankes W, Amieva A (1992) Moesin, a new cytoskeletal protein and constituent of filopodia: its role in cellular functions. Kidney Int 41: 665-670

13. Dunster LM, Schneider-Sichaulies J, Löffler S, Lankes W, Schwarz Albiez R, Lottipeich F, ter Meulen V (1994) Moesin: a cell membrane protein linked with susceptibility to measles virus infection. Virology 198:265-274

14. Johnstone RW, Russell SIM, Loveland BE, McKenzie IFC (1993) Polymorphic exprission of CD46 protein isoforms due to tissue specific RNA splicing. Mol Immunol 30:1231-1241

15. Moscona A, Peluso RW (1991) Fusion propertics of cells persistently infected with human parainfluenza virus type 3: participation of hemagglutinin-neuroaminidase in membrane fusion. J Virol 65:2773-2777

16. Crise B, Buonocore L, Fose JK (1990) CD4 is retained in the endoplasmatic reticulum by the human immunodeficiency virus type 1 glycoprotein precursor. J Virol 64: 5585-5593

17. Hirano A (1992) Subacutt: sclerosing panencephalitis virus dominantly interferes with replication of wild type measles virus in a mixed infection: implication for viral persistence. J Virol 66:1891-1898 
18. Schneider-Schaulies S, Schneider-Schaulies J, Dunster LM, ter Meulen V (1994) Measles virus gene expression in neural cells. Curr Top Microbiol Immunol, in press

19. Cattaneo R, Rebmann G, Schmid A, Baczko $K$, ter Meulen V, Billeter MA (1987) Altered transcription of a defective measles virus genome derived from a diseased human brain. EMBO J 6:681-687

20. Cattanco R, Rebmann G, Baczko K, ter Mculen V, Billeter MA (1987) Altered ratios of measles virus transcripts in diseased human brains. Virology 160:523-526

21. Moycr SA, Baker SC, Horikami SM (1990) Host cell proteins required for measles virus reproduction. J Gen Virol 71.775-783

22. Liebert UG, Baczko K, Budka H, ter Meulen V (1986) Restricted expression of measles virus proteins in brains from cases of subacutc sclerosing panencephalitis. J Gen Virol 67:2435-2444

23. Schneider-Schaulies S, Liebert UG, Baczko K, ter Meulen V (1990) Restricted expression of measles virus in primary rat astroglial cells. Virology 177:802-806

24. Schneider-Schaulies S, Schneider-Schaulies J, Bayer M, Löfler S, ter Meulen V (1993) Spontaneous and differentiation dependent regulation of measles virus gene expression in human glial cells. J Virol 67:3375-3383

25. Liebert UG, Schneider-Schaulies S, Baczko K, ter Meulen V (1990) Antibody-induced restriction of viral gene expression in measles encephalitis in rats. J Virol 64:706-713

26. Yoshikawa Y, Yamanouchi K (1984) Effects of papaverine treatment on replication of measles virus in human neural and non-neural cells. J Virol 50:489-496

27. Schneider-Schaulies S, Liebert UG, Baczko K, Cattaneo R, Billeter M, ter Meulen V (1989) Restriction of measles virus gene expression in acute and subacute encephalitis of Lewis rats. Virology 171:525-534

28. Barrett PN, Koschel K, Carter M, ter Meulen V (1985) Effect of measles virus antibodies on a measles SSPE virus persistently infected C6 rat-glioma cell linc. J Gen Virol $66: 1411-1421$

29. Rager-Zisman B, Egan JE, Kress Y, Bloom BR (1984) Isolation of cold-sensitive mutants of measles virus from persistently infected murine neuroblastoma cells. J Virol $51: 845-855$

30. Schneider-Schaulies S, Liebert UG, Segev Y, Rager-Zisman B, Wolfson M, ter Meulen V (1992) Antibody-dependent transcriptional regulation of measles virus in persistently infected neural cells. J Virol 66:5534-5541

31. Levine B, Hardwick JM, Trapp BD, Crawford TO Bollinger RC, Griffin DE (1991) Antibody mediated clearance of alphavirus infection from neurons. Science 254:856-860

32. Weinmann-Dorsch C, Koschel K (1989) Coupling of viral membrane proteins to phosphatidylinositide signalling system. FEBS Lett 247:185-188

33. Segev $Y$, Rager-Zisman B, Isakov N, Schneider-Schaulies $S$, ter Meulen V, Udem SA, Segal S, Wolfson M (1994) Reversal of measles virus mediated increase of phosphorylating activity in persistently infected mouse neuroblastoma cells by anti-measles antibodies. J Gen Virol, in press

34. Vanionpää R, Hypiä T, Akerman KEO (1991) Early signal transduction in measles virus-infected lymphocytes is unaltered, but second messengers activate virus replication. J Virol 65:6743-6748

35. Schneider-Schaulies J, Schneider-Schaulies S, ter Meulen V (1993) Differential induction of cytokines by primary and persistent measles virus infections in human glial cells. Virology 195:219-228

36. Fujii N, Oguma K, Kimura K, Yamashita T, Koishida S, Fujinaga K, Yashik T (1988) Oligo-2', 5'-adenylate synthetase activity in K562 cell lines persistently infected with measles or mumps virus. J Gen Virol 69:2085-2091

37. Crespi M, Chiu MN, Schoub BD, Lyons SF (1986) Effects of Interferon on Vero cells persistently infected with SSPE Virus and lytically infected with measles virus. Arch Virol 90:87-96

38. Kraus E, Schneider-Schaulies S, Miyasaka M, Tamatani T, Sedgwick J (1992) Augmentation of major histocompatibility complex class I and ICAM-I expression on glial cells following measles virus infection: evidence for the role of type-1 interferon. Eur J Immunol 22:175-182

39. Schneider-Schaulies S, Schneider-Schaulies J, Schuster A, Bayer M, Pavlovic J, ter Meulen V (1994) Cell type specific MxA-mediated inhibition of measles virus transcription in human brain cells. Submitted

40. Schnorr JJ, Schneider-Schaulies S, Simon-Jökicke A, Pavlovic J, Horisberger MA, ter Meulen V (1993) MxA dependent inhibition of measles virus glycoprotein synthesis in a stably transfected human monocytic cell line. J Virol 67:4760-4768

41. Staeheli P, Pavlovic J (1992) Inhibition of vesicular stomatitis virus mRNA synthesis by human MxA protein. J Virol 65:4498-4501

42. Moyer SA, Baker SC, Lessard JL (1986) Tubulin: a factor necessary for the synthesis of both Sendai virus and vesicular stomatitis virus RNA. Proc Natl Acad Sci USA 83: 5404-5409

43. De BP, Burdsall AL, Banerjee AK (1993) Role of cellular actin in human parainfluenza virus type 3 genome transcription. J Biol Chem 268:5703-5710

44. Leopardi R, Hukkanen V, Vanionpää R, Salmi AA (1993) Cell proteins bind to sites within the $3^{\prime}$ noncoding region and the positive strand leader sequence of measles virus RNA. J Virol 67:785-790

.45. Barik S, Banerjee AK (1992) Sequential phosphorylation of the phosphoprotein of vesicular stomatitis virus by cellular and viral protein kinases is essential for transcription activation. J Virol 66:1109-1118

46. Sleat DE, Chikkala NF, Gautam S, Banerjee AK (1993) Restricted replication of vesicular stomatitis virus in $T$ lymphocytes is coincident with a deficiency in a cellular protein kinase required for viral transcription. J Gen Virol 73:3125-3132

47. Rima BK (1983) The proteins of morbilliviruses. J Gen Virol 64:1205-1219

48. Gombart AF, Hirano A, Wong TC (1992) Expression and properties of the $\mathrm{V}$ protein in acute measles virus and subacute sclerosing panencephalitis virus strains. Virus Res 25:63-78

49. Wilde TF, Buckland $R$ (1994) Measles virus protein function. Curr Top Microbiol Immunol, in press

50. Horikami SM, Curran J, Kolakofsky D, Moyer SA (1992) Complexes of the Sendai virus NP/P and P/L proteins are required for defective interfering particle genome replication in vitro. J Virol 66:4901-4908

51. Curran J, Boeck R, Kolakofsky D (1991) The Sendai virus $P$ gene expresses both an essential protein and an inhibitor of RNA synthesis by shufling modules via mRNA editing. EMBO J 10:3079-3085

52. Horikami SM, Moyer SA (1991) Synthesis of leader RNA and editing of the $P$ mRNA during transcription by purified measles virus. J Virol 65:5342-5347

53. Ayata M, Hirano A, Wong TC (1989) Structural defect linked to non-random mutations in the matrix gene of Biken strain subacute scierosing panencephalitis virus defined by cDNA cloning and expression of chimeric genes. J Virol $63: 1162-1173$

54. Cattaneo R, Schmid A, Eschle D, Baczko K, ter Meulen V, Billeter MA (1988) Biased hypermutation and other genetic 
changes in defective measles viruses in human brain infections. Cell 55:255-265

55. Wong TC, Ayata M, Ueda S, Hirano A (1991) Role of biased hypermutation in evolution of subacute sclerosing panencephalitis virus from progenitor acute measles virus. J Virol 65:2191-2199

56. Bass BL, Weintraub H, Cattaneo R, Billeter MA (1989) Biased hypermutation of viral genomes could be due to the unwinding/modification of the double stranded RNA. Cell $56: 331$

57. Billeter MA, Cattaneo R (1991) Mutations and A/I hypermutations, in Measles Virus Persistent Infections. The paramyxoviruses (Kingsbury D, ed), pp 323-345. Plenum, New York

58. O'Hara PJ, Nichol ST, Horodyski FM, Holland JJ (1984) Vesicular stomatitis virus defective interfering particles can contain extensive genomic sequence rcarrangements and base substitutions. Cell 36:915-924

59. Murphy DG, Dimock K, Kang CY (1991) Numerous transitions in human parainfluenza virus 3 RNA recovered from persistently infected cells. Virology 181:760-763

60. Antic D, Lim BU, Kang CY (1992) Molecular characterization of the $M$ genomic segment of the Seoul 80-39 virus: nucleotide and amino acid sequence comparisons with other hantaviruses reveal the evolutionary pathway. Virus Res 19:47-58

61. Wagner RW, Nishikura K (1988) Cell cycle expression of RNA duplex unwindase activity in mammalian cells. Mol Cell Biol 8:770-777

62. Wagner RW, Smith JE, Cooperman BS, Nishikura K (1989) A double stranded RNA unwinding activity introduces structural alterations by means of adenosine to inosine conversions in mammalian cells and Xenopus eggs. Proc Natl Acad Sci USA 86:2647-2651

63. Nishikura K, Yoo C, Kim U, Murray JM, Estes PA, Cash FE, Liebhaber SA (1991) Substrate specificity of the dsRNA unwinding/modifying activity. EMBO J 6: 3523-3532

64. Rataul SM, Hirano A, Wong TC (1992) Irreversible modification of measles virus RNA in vitro by nuclear
RNA-unwinding activity in human neuroblastoma cells. J Virol 66:1769-1773

65. Ecker A, ter Meulen V, Schneider-Schaulies S (1994) Differentiation dependent regulation of unwinding/modifying activity for measles virus in neural cells. Submitted

66. Merrick WC (1992) Mechanism and regulation of eucaryotic protein synthesis. Microbiol Rev 56:291-315

67. Ogura H, Rima BK, Baczko K, ter Meulen V (1988) Restricted synthesis of the fusion protein of measles virus at elevated temperatures. J Gen Virol 69:925-929

68. Miller CA, Carrigan DR (1982) Reversible repression and activation of measles virus infection in neural cells. Proc Natl Acad Sci 79:1629-1633

69. Staeheli $P$ (1990) Interferon-induced proteins and the antiviral state. Adv Virus Res 38:147-200

70. Leopardi R, Hyypiä T, Vainionpää R (1992) Effect of interferon- $\alpha$ on measles virus replication in human peripheral blood mononuclear cells. APMIS 100:125-131

71. Huber M, Cattaneo R, Spielhofer P, Örvell C, Norrby E, Messerli M, Perriard JC, Billeter MA (1991) Measles virus phosphoprotein retains the nucleocapsid protein in the cytoplasm. Virology 185:299-308

72. Hirano A, Wang AH, Gombart AF, Wong TC (1992) The matrix proteins of neurovirulent subacute sclerosing panencephalitis virus and its acute measles progenitor are functionally different. Proc Natl Acad Sci USA 89: 8745-8749

73. Hirano A, Ayata M, Wang AH, Wong TC (1993) Functional analysis of matrix proteins expressed from cloned genes of measles virus variants that cause subacute sclerosing panencephalitis reveals a common defect in nucleocapsid binding. J Virol 67:1848-1853

74. Suryanarayana K, Baczko K, ter Meulen V, Wagner RR (1994) Transcription inhibition and other properties of matrix proteins expressed by $M$ genes cloned from measles viruses and diseased human brains. J Virol 68 : 1532-1543

75. Cattaneo R, Rose JK (1993) Cell fusion by the envelope glycoproteins of persisten: measles viruses which caused lethal human brain diseases. J Virol 67:1493-1502 